\title{
The Effect of Anti-Tumor Necrosis Factor-Alpha Treatment on Muscle Performance and Endurance in Patients With Ankylosing Spondylitis: A Prospective Follow-Up Study
}

\author{
Musa DEMİRKAPI, Mustafa Turgut YILDIZGÖREN, Hayal GÜLER, Ayşe Dicle TURHANOĞLU \\ Department of Physical Medicine and Rehabilitation, Medical Faculty of Mustafa Kemal University, Hatay, Turkey
}

\begin{abstract}
Objectives: This study aims to evaluate muscle performance by using isokinetic dynamometer before and at third month of anti-tumor necrosis factor-alpha treatment in ankylosing spondylitis patients.

Patients and methods: Thirty ankylosing spondylitis patients ( 23 males, 7 females; mean age $39.3 \pm 8.6$ years; range 18 to 45 years) starting on antitumor necrosis factor-alpha treatment and 30 healthy controls ( 23 males, 7 females; mean age $39.1 \pm 8.8$ years; range 18 to 48 years) with similar age, body mass index, and sex were enrolled. The clinical anthropometric measurements of chest expansion, lumbar Schober test, hand-finger floor distance and visual analog scale-global, C-reactive protein, erythrocyte sedimentation rate, Ankylosing Spondylitis Disease Activity Score-C-reactive protein and Ankylosing Spondylitis Disease Activity Score-erythrocyte sedimentation rate, Bath Ankylosing Spondylitis Disease Activity Index, Bath Ankylosing Spondylitis Metrology Index, Bath Ankylosing Spondylitis Disease Activity Index, Bath Ankylosing Spondylitis Metrology Index were determined before and at third month of the treatment.

Results: There was no statistically significant difference in age, sex and, body mass index between the groups ( $p>0.05$ ). A statistically significant difference was detected between $60 \%$ second and $180 \%$ second peak torque in angular velocity of flexor and extensor muscles ( $p<0.05$ ). A significant difference was detected in respect to total work of patients with $180 \%$ second peak torque in angular velocity of flexor and extensor muscles ( $\mathrm{p}<0.05$ ). There was a statistically significant difference between the findings of $60 \%$ second and $180 \%$ second peak torque in angular velocity of flexor and extensor muscles $(p<0.05)$. Isokinetic test results were better at third month after treatment than before treatment.

Conclusion: The results of this study showed that both functional limitations and performance and endurance of muscles may be improved with anti-tumor necrosis factor-alpha treatment in ankylosing spondylitis patients.

Keywords: Ankylosing spondylitis; anti-tumor necrosis factor-alpha treatment; isokinetic test; muscle performance.
\end{abstract}

Ankylosing spondylitis (AS) is a chronic rheumatic condition characterized by inflammatory back pain and stiffness. Tumor necrosis factor plays an important role in the pathogenesis of AS disease that is accompanied by the loss of muscle strength. Several studies in humans have shown a relationship between proinflammatory cytokine levels and muscle mass. ${ }^{1,2}$ In AS patients, restrictions in joint mobility, particularly of the spine, have been well documented. ${ }^{3,4}$ Cachexia or muscle loss, the accelerated loss of skeletal muscle in the context of a chronic inflammatory response, is a common feature of other rheumatic conditions, although body composition studies have not consistently demonstrated cachexia in AS populations. ${ }^{5-7}$

When reduced physical activity and chronic inflammation are taken into consideration, AS patients are at risk of accelerated muscle loss. By leading to reduced muscle power, resistance, and physical activity, the loss of muscle mass contributes to the restriction in functional independence and daily living activities. Although the mechanism of muscle loss is not clear, it has been thought that anti-tumor necrosis 
factor-alpha (anti-TNF- $\alpha$ ) causes muscle loss by stimulating muscle protein destruction and inhibiting myogenic differentiation. ${ }^{3}$ In contrast, there are also studies showing no change in the muscle mass of AS patients. ${ }^{6}$ To the best of our knowledge, the effects of anti-TNF- $\alpha$ treatment on muscle strength and endurance have not been studied in patients with AS yet. Therefore, in this study, we aimed to evaluate muscle performance by using isokinetic dynamometer before and at third month of anti-TNF- $\alpha$ treatment in ankylosing spondylitis patients.

\section{PATIENTS AND METHODS}

This prospective study was conducted between June 2015 and June 2016 at Medical Faculty of Mustafa Kemal University. The study group comprised 30 AS patients (23 males, 7 females; mean age $39.3 \pm 8.6$ years; range 18 to 45 years) treated with anti TNF- $\alpha$. These patients were disease-modifying antirheumatic drugs-resistant or intolerant, with AS diagnosed by a physiatrist in accordance with the classification criteria for axial spondyloarthropathy. A control group was formed of 30 healthy individuals (23 males, 7 females; mean age $39.1 \pm 8.8$ years; range 18 to 48 years) matched with the study group for age, sex, and body mass index.

Patients with severe disease activity, disability, renal or liver diseases, uncontrolled hypertension, heart failure, malignancy, pregnancy, other disorders (e.g., thyroid, parathyroid disorders, osteoporosis), and usage of drugs that can affect skeletal metabolism, any history of trauma and/or surgery of the lower limbs were excluded. The study was approved by the Local Ethical Committee of Medical Faculty of Mustafa Kemal University. A written informed consent was obtained from each patient. The study was conducted in accordance with the principles of the Declaration of Helsinki.

Participant age, sex, smoking history, and weekly exercise frequency were self-reported. Subjects with AS were also asked about symptom duration, time since diagnosis, and current medication usage. Disease activity was measured on the Bath Ankylosing Spondylitis Disease Activity Index. ${ }^{8}$ Spinal flexibility was assessed with the Bath Ankylosing Spondylitis Metrology Index. ${ }^{9}$ The clinical anthropometric measurements of chest expansion, lumbar Schober test, hand-finger floor distance and the visual analog scale global, C-reactive protein, erythrocyte sedimentation rate, Ankylosing Spondylitis Disease Activity ScoreC-reactive protein and Ankylosing Spondylitis Disease Activity Score-erythrocyte sedimentation rate ${ }^{10}$ values were calculated before and after treatment.

Isokinetic muscle performance was measured using a calibrated isokinetic test device named Humac $^{\circledR} /$ NormTM Testing \& Rehabilitation System (Computer Sports Medicine Inc., Stoughton, MA, USA). The knee extensor/flexor muscle group isokinetic muscle strength [peak torque (PT)] of both groups was evaluated using a calibrated isokinetic dynamometer.

Before the isokinetic measurement, the subjects were seated on the dynamometric chair and stabilized with waist and chest belts in $90^{\circ}$ sitting position. After performing five submaximal warmup contractions, concentric PT values of the quadriceps and hamstrings at $60^{\circ}$ and $180^{\circ}$ per second angular velocities, total work (TW), hamstring strength to quadriceps strength ratio, and muscle endurance were evaluated. The isokinetic test protocol included five repeats at $60^{\circ}$ per second, 30 seconds of rest, and 15 repeats at $180^{\circ}$ per second.

\section{Statistical analysis}

Statistical analyses were conducted with IBM SPSS software version 20.0 (IBM Corp., Armonk, NY, USA). Data were expressed as mean \pm standard deviation. After checking normal distribution with the Kolmogorov-Smirnov test, independent t-test was used to compare the baseline parameters between the treatment and control groups. Paired t-tests and Wilcoxon signed rank tests were used to compare baseline and third month after treatment values where appropriate. The results were for those who completed treatment. Statistical significance was accepted as $\mathrm{p}<0.05$.

\section{RESULTS}

Clinical and laboratory features of the participants are presented in Table 1 . There was no statistically significant difference between the groups for age, sex, height, weight, and body 
Table 1. Demographic and laboratory features of study groups

\begin{tabular}{|c|c|c|c|c|c|c|c|}
\hline & \multicolumn{3}{|c|}{ AS patients $(n=30)$} & \multicolumn{3}{|c|}{ Controls $(n=30)$} & \multirow[b]{2}{*}{$p$} \\
\hline & $\mathrm{n}$ & $\%$ & Mean \pm SD & $\mathrm{n}$ & $\%$ & Mean \pm SD & \\
\hline Age (year) & & & $39.3 \pm 8.6$ & & & $39.1 \pm 8.8$ & 0.918 \\
\hline Gender & & & & & & & 1.000 \\
\hline Male & 23 & - & - & 23 & - & - & \\
\hline Female & 7 & - & - & 7 & - & - & \\
\hline Height $(\mathrm{cm})$ & - & - & $169.9 \pm 6.7$ & - & - & $170.9 \pm 9.1$ & 0.588 \\
\hline Weight (kg) & - & - & $76.5 \pm 11.3$ & - & - & $77.6 \pm 11.6$ & 0.696 \\
\hline Body Mass Index $\left(\mathrm{kg} / \mathrm{m}^{2}\right)$ & - & - & $26.5 \pm 3.2$ & - & - & $26.5 \pm 3.6$ & 0.939 \\
\hline Disease duration, years & - & - & $7.5 \pm 7.9$ & - & - & - & - \\
\hline \multicolumn{8}{|l|}{ Medication } \\
\hline Nonsteroidal anti-inflammatory drug & 6 & 20 & - & - & - & - & - \\
\hline Nonsteroidal anti-inflammatory drug + sulfasalazine & 23 & 76.6 & - & - & - & - & - \\
\hline Methotrexate & 1 & 3.4 & - & - & - & - & - \\
\hline \multicolumn{8}{|l|}{ Anti-tumor necrosis factor-alpha treatment } \\
\hline Infliximab & 15 & 50 & - & - & - & - & - \\
\hline Adalimumab & 12 & 40 & - & - & - & - & - \\
\hline Etanercept & 3 & 10 & - & - & - & - & - \\
\hline Duration of drug use (years) & & & $4.1 \pm 5.2$ & & & - & - \\
\hline Thyroid stimulating hormone (uIU/mL) & - & - & $2.1 \pm 1.5$ & - & - & $2.3 \pm 1.2$ & 0.804 \\
\hline Alanine aminotransferase (U/L) & - & - & $32 \pm 20$ & - & - & $30 \pm 21$ & 0.745 \\
\hline Aspartate aminotransferase (U/L) & - & - & $29 \pm 16$ & - & - & $26.0 \pm 14$ & 0.662 \\
\hline Calcium (mg/dL) & - & - & $8.8 \pm 0.2$ & - & - & $9.0 \pm 0.3$ & 0.858 \\
\hline Phosphorus (mg/dL) & - & - & $2.9 \pm 0.3$ & - & - & $2.8 \pm 0.2$ & 0.974 \\
\hline Parathyroid hormone $(\mathrm{pg} / \mathrm{mL})$ & - & - & $77 \pm 28$ & - & - & $70 \pm 25$ & 0.272 \\
\hline 25-hydroxyvitamin D (ng/mL) & - & & $21.0 \pm 10.9$ & - & - & $19.6 \pm 14.6$ & 0.858 \\
\hline Alkaline phosphatase (IU/L) & - & - & $66 \pm 21$ & - & - & $76 \pm 18$ & 0.373 \\
\hline Creatine kinase $(\mathrm{U} / \mathrm{L})$ & - & - & $112 \pm 29$ & - & - & $78 \pm 24$ & 0.106 \\
\hline
\end{tabular}

mass index. Disease duration and duration of medication use for AS group were mean 7.5 \pm 7.9 years and mean $4.1 \pm 5.2$ years, respectively. Before the anti-TNF- $\alpha$ treatment, 20\% $(n=6)$ were taking nonsteroidal anti-inflammatory drugs only, $76.6 \%(\mathrm{n}=23)$ were taking nonsteroidal anti-inflammatory drugs + sulfasalazine, and one patient was taking methotrexate treatment only. Overall, 15 patients (50\%) were treated with infliximab, 12 (40\%) with adalimumab, and three (10\%) with etanercept.

Baseline isokinetic test results of the groups are given in Table 2. The angular velocity PT values of the extensor muscles at $60 \%$ second and $180 \%$ second and the TW values at $180 \%$ second angular velocity were statistically significantly lower in the AS group than in the control group $(\mathrm{p}<0.05)$.

Table 2. Isokinetic test values of ankylosing spondylitis patients and controls

\begin{tabular}{|c|c|c|c|}
\hline \multirow[b]{2}{*}{ Measurement } & \multirow{2}{*}{$\frac{\text { AS patients }}{\text { Mean } \pm \text { SD }}$} & \multirow{2}{*}{$\begin{array}{l}\text { Controls } \\
\text { Mean } \pm \text { SD }\end{array}$} & \multirow[b]{2}{*}{$p$} \\
\hline & & & \\
\hline \multicolumn{4}{|l|}{ Flexors } \\
\hline $60 \%$ sec peak torque $(\mathrm{Nm})$ & $56.2 \pm 21.7$ & $84.1 \pm 33.1$ & $* 0.000$ \\
\hline $180^{\circ} / \mathrm{sec}$ peak torque $(\mathrm{Nm})$ & $35.0 \pm 13.4$ & $51.2 \pm 20.2$ & $* 0.001$ \\
\hline Fatigue index (\%) & $17.4 \pm 20.2$ & $26.3 \pm 31.3$ & 0.197 \\
\hline Total work (Joule) & $415.8 \pm 178.9$ & $550.4 \pm 248.6$ & $* 0.019$ \\
\hline \multicolumn{4}{|l|}{ Extensors } \\
\hline $60 \%$ sec peak torque $(\mathrm{Nm})$ & $108.9 \pm 38.1$ & $158.9 \pm 52.1$ & $* 0.000$ \\
\hline $180^{\circ} / \mathrm{sec}$ peak torque $(\mathrm{Nm})$ & $57.7 \pm 22.5$ & $90.2 \pm 33.4$ & $* 0.000$ \\
\hline Fatigue index (\%) & $19.7 \pm 22.9$ & $21.5 \pm 21.9$ & 0.762 \\
\hline Total work (Joule) & $623.8 \pm 229.2$ & $1038.0 \pm 407.4$ & $* 0.000$ \\
\hline \multicolumn{4}{|c|}{ Hamstring: Quadriceps peak torque ratio } \\
\hline $60 \% \mathrm{sec}$ & $53.2 \pm 14.4$ & $53.2 \pm 12.8$ & 1.000 \\
\hline $180 \% \mathrm{sec}$ & $63.6 \pm 15.8$ & $59.9 \pm 24.8$ & 0.499 \\
\hline
\end{tabular}




\begin{tabular}{|c|c|c|c|}
\hline \multirow[b]{2}{*}{ Measurement } & \multicolumn{2}{|c|}{ AS patients } & \multirow[b]{2}{*}{$p$} \\
\hline & Baseline & 3-month follow-up & \\
\hline \multicolumn{4}{|l|}{ Flexors } \\
\hline $60 \%$ sec peak torque $(\mathrm{Nm})$ & $56.2 \pm 21.7$ & $69.2 \pm 25.7$ & $* 0.000$ \\
\hline $180 \%$ sec peak torque $(\mathrm{Nm})$ & $35.0 \pm 13.4$ & $45.8 \pm 17.5$ & ${ }^{*} 0.000$ \\
\hline Fatigue index (\%) & $17.4 \pm 20.2$ & $25.6 \pm 19.1$ & ${ }^{*} \mathbf{0 . 0 1 3}$ \\
\hline Total work (Joule) & $415.8 \pm 178.9$ & $559.9 \pm 217.5$ & $* 0.000$ \\
\hline \multicolumn{4}{|l|}{ Extensors } \\
\hline $60 \%$ sec peak torque $(\mathrm{Nm})$ & $108.9 \pm 38.1$ & $121.7 \pm 42.8$ & *0.014 \\
\hline $180^{\circ}$ sec peak torque $(\mathrm{Nm})$ & $57.7 \pm 22.5$ & $63.3 \pm 25.3$ & ${ }^{*} 0.021$ \\
\hline Fatigue index (\%) & $19.7 \pm 22.9$ & $24.3 \pm 19.6$ & 0.365 \\
\hline Total work (Joule) & $623.8 \pm 229.2$ & $686.5 \pm 257.9$ & 0.055 \\
\hline \multicolumn{4}{|c|}{ Hamstring muscle: Quadriceps peak torque ratio } \\
\hline $60 \% \mathrm{sec}$ & $53.2 \pm 14.4$ & $61.0 \pm 25.9$ & 0.102 \\
\hline $180 \% \mathrm{sec}$ & $63.6 \pm 15.8$ & $74.6 \pm 17.3$ & $* 0.003$ \\
\hline
\end{tabular}

Isokinetic test values of the AS group before the anti-TNF- $\alpha$ treatment and at third month of the treatment are shown in Table 3. A statistically significant increase was detected in the $60 \%$ second and $180 \%$ second angular velocity PT values in the flexor and extensor muscles around the knee at third month of treatment compared to baseline values $(p<0.05)$. A statistically significant increase was detected in the $180 \%$ second angular velocity hamstring strength to quadriceps strength $(\mathrm{H} / \mathrm{Q})$ ratios at third month of treatment $(p<0.05)$. A statistically significant increase was detected in the fatigue index (FI) and TW values of the flexor muscles at third month of treatment $(p<0.05)$.

\section{DISCUSSION}

In this study, a comparison was made before and at third month of anti-TNF- $\alpha$ treatment for the strength and endurance values of the extensor and flexor muscle groups around the knee in AS patients with axial involvement who had started this treatment because disease activity had not been suppressed by disease-modifying antirheumatic drugs. Three months after the start of anti-TNF- $\alpha$ treatment, a statistically significant increase was determined in the $60 \%$ second and $180 \%$ second angular velocity PT values in the knee flexor and extensor muscle groups in the AS patients. In addition, a statistically significant increase was determined in the $180 \%$ second angular velocity hamstring strength to quadriceps strength (H/Q) ratios and FI values.

Although there are cross-sectional studies in the literature showing reduced performance of the knee and ankle muscles in AS patients, to the best of our knowledge, no prospective study has been performed evaluating the effect of anti-TNF- $\alpha$ treatment on muscle performance and endurance in AS patients. ${ }^{11}$ Therefore, the current study is the first to evaluate the effect of anti-TNF- $\alpha$ treatment on muscle performance and endurance in AS patients.

Although the effect of TNF- $\alpha$ on muscle strength is not fully known, there are studies which have reported that the suppression of TNF- $\alpha$ has positive effects on muscle strength. Ermolova et al. ${ }^{12}$ determined increased muscle strength after treatment of $3 \mathrm{mg} / \mathrm{kg}$ infliximab in rats with Duchenne muscular dystrophy where the TNF- $\alpha$ level was high. In another placebo-controlled study in a healthy population, a significant increase was determined in the muscle strength of the group given etanercept before intense exercise compared to the control group. The increased muscle strength was seen without any change in the pain parameters. ${ }^{13}$ In a study by Briot et al., ${ }^{14}$ increased lean body mass was observed after antiTNF- $\alpha$ treatment in AS patients.

Stasko et al. ${ }^{15}$ showed that muscle strength was reduced by TNF- $\alpha$ increasing nitric oxide and oxygen radicals through neural type nitric oxide synthesis. Another known effect of TNF- $\alpha$ on 
muscles is muscle atrophy. Long-term exposure to TNF- $\alpha$ activates the ubiquitin-proteasome pathway with a catabolic effect, thereby causing protein loss and reduced cell size. This reduction in muscle size is reflected in reduced muscle strength. ${ }^{16}$ In the current study, the baseline isokinetic test values of the AS patients were lower than those of the healthy control group. In addition, an improvement was seen in the disease activity and isokinetic test values with the antiTNF- $\alpha$ treatment. These results of the negative effect of TNF- $\alpha$ on muscle are supported by data in literature.

Muscle strength is measured more efficiently with tests performed with low angular velocities, while high angular velocities are useful for the detection of functional status and endurance of the muscle. There is no standard model for isokinetic test measurement in AS. In this study, 60\% second and $180 \%$ second angular velocities were used. In studies where the muscle strength of AS patients has been measured with isokinetic dynamometer, the muscle strength has been shown to be low compared to the healthy population. ${ }^{11}$ Langen et $\mathrm{al}^{3}$ reported that TNF- $\alpha$, which is a proinflammatory cytokine, plays an important role in the pathogenesis of rheumatismal diseases and has been held responsible for the pathogenesis of muscle loss in AS patients. It is thought that TNF- $\alpha$ causes muscle loss by stimulating the destruction of muscle protein and inhibiting myogenic differentiation.

Pain, inflammation, and stiffness play a major role in muscle performance loss in AS patients. Muscle weakness develops in the first week of non-movement and increases rapidly. Reduced physical activity or inactivity of muscles results in atrophy and this reduced functional capacity is caused by reduced neuromuscular performance. In a study of inflammatory diseases, a reduction in dynamic and isometric muscle strength was seen in the early stages of disease. Catabolic stimuli including cytokines, such as interleukin-6, interleukin-1 and TNF- $\alpha$, increase together with inflammation and each of these causes muscle protein destruction. ${ }^{11}$ In the current study, the findings that the $60 \%$ second and $180 \%$ second angular velocity PT values of the flexor and extensor group muscles were lower in the AS patients than in the control group before antiTNF- $\alpha$ treatment support this view.
Another reason for reduced muscle performance is fatigue, which is a constitutional symptom. Muscle fatigue is responsible for loss of motor control, and changes in posture and balance. When the relationship between fatigue and postural changes is taken into consideration, fatigue may play a significant role in the postural changes in AS patients. A limited number of studies in the literature have reported that reduced muscle resistance has been observed in AS. Accordingly, muscle weakness in AS patients may be the cause or the result of fatigue. In the current study, although the FI values of the flexor and extensor muscles of the AS patients were lower than those of the control group, the difference was not statistically significant. Following anti-TNF- $\alpha$ treatment, although the FI values were high compared to the baseline, only the FI increase in the flexor group muscles was statistically significant. With the increased muscle strength following anti-TNF- $\alpha$ treatment, increased TW is expected. In the current study, the TW values were found to increase in parallel with the increased muscle strength.

There are some limitations to this study. The first is that no power analysis was applied before the study. Secondly, it is debatable whether a three-month period of treatment is sufficient to evaluate muscle performance. Thirdly, AS patients with active disease (Bath Ankylosing Spondylitis Disease Activity Index >4) were included in the study. Finally, the level of physical activity affected by muscle performance was not calculated. In the current study, although all the AS patients were given posture exercises and breathing exercises, they were not questioned as to whether they had performed the exercises regularly. Even though this lack of questioning the exercise status can be seen as a significant limitation of the study, as the exercises given did not include strengthening exercises, the increased muscle strength and endurance that was seen within three months can be attributed to the muscles having been protected from the effect of TNF- $\alpha$. As there was an improvement in functional activity after anti-TNF- $\alpha$ treatment, the treatment could have contributed to this effect.

In conclusion, in addition to the functional disability, destruction of the axial spine and peripheral joints and ankylosis in AS patients, muscle weakness and reduced endurance are 
further possible problems that may be faced by these patients. The results of this study have shown that both functional limitations and performance and endurance of muscles can be improved with anti-TNF- $\alpha$ treatment in AS patients.

\section{Declaration of conflicting interests}

The authors declared no conflicts of interest with respect to the authorship and/or publication of this article.

\section{Funding}

The authors received no financial support for the research and/or authorship of this article.

\section{REFERENCES}

1. Roubenoff R, Roubenoff RA, Cannon JG, Kehayias JJ, Zhuang H, Dawson-Hughes B, et al. Rheumatoid cachexia: cytokine-driven hypermetabolism accompanying reduced body cell mass in chronic inflammation. J Clin Invest 1994;93:2379-86.

2. Raina P, Matharoo K, Kumar A, Sarangal P, Sharma R, Bhanwer AJS. Association of Tumor Necrosis Factor-Alpha -308 G>A Polymorphism With Rheumatoid Arthritis in Two North Indian Cohorts. Arch Rheumatol 2014;29:241-9.

3. Langen RC, Van Der Velden JL, Schols AM, Kelders MC, Wouters EF, Janssen-Heininger YM. Tumor necrosis factor-alpha inhibits myogenic differentiation through MyoD protein destabilization. FASEB J 2004;18:227-37.

4. Erdogdu DD, Bal A, Karaahmet O, Erkoç S, Yalçın T, Çakc1 A. Efficacy of tumor necrosis factor inhibitors in patients with ankylosing spondylitis. Arch Rheumatol 2014;29:257-66.

5. van Echteld I, Cieza A, Boonen A, Stucki G, Zochling $\mathrm{J}$, Braun $\mathrm{J}$, et al. Identification of the most common problems by patients with ankylosing spondylitis using the international classification of functioning, disability and health. J Rheumatol 2006;33:2475-83.

6. Marcora S, Casanova F, Williams E, Jones J, Elamanchi R, Lemmey A. Preliminary evidence for cachexia in patients with well-established ankylosing spondylitis. Rheumatology (Oxford) 2006;45:1385-8.
7. Plasqui G, Boonen A, Geusens P, Kroot EJ, Starmans $\mathrm{M}$, van der Linden $\mathrm{S}$. Physical activity and body composition in patients with ankylosing spondylitis. Arthritis Care Res (Hoboken) 2012;64:101-7.

8. Garrett S, Jenkinson T, Kennedy LG, Whitelock H, Gaisford P, Calin A. A new approach to defining disease status in ankylosing spondylitis: the Bath Ankylosing Spondylitis Disease Activity Index. J Rheumatol 1994;21:2286-91.

9. Jenkinson TR, Mallorie PA, Whitelock HC, Kennedy LG, Garrett SL, Calin A. Defining spinal mobility in ankylosing spondylitis (AS). The Bath AS Metrology Index. J Rheumatol 1994;21:1694-8.

10. Lukas C, Landewé R, Sieper J, Dougados M, Davis J, Braun J, et al. Development of an ASAS-endorsed disease activity score (ASDAS) in patients with ankylosing spondylitis. Ann Rheum Dis 2009;68:18-24.

11. Sahin N, Ozcan E, Baskent A, Karan A, Kasikcioglu E. Muscular kinetics and fatigue evaluation of knee using by isokinetic dynamometer in patients with ankylosing spondylitis. Acta Reumatol Port 2011;36:252-9.

12. Ermolova NV, Martinez L, Vetrone SA, Jordan MC, Roos KP, Sweeney HL, et al. Long-term administration of the TNF blocking drug Remicade (cV1q) to $\mathrm{mdx}$ mice reduces skeletal and cardiac muscle fibrosis, but negatively impacts cardiac function. Neuromuscul Disord 2014;24:583-95.

13. Rice TL, Chantler I, Loram LC. Neutralisation of muscle tumour necrosis factor alpha does not attenuate exercise-induced muscle pain but does improve muscle strength in healthy male volunteers. Br J Sports Med 2008;42:758-62.

14. Briot K, Garnero P, Le Henanff A, Dougados M, Roux C. Body weight, body composition, and bone turnover changes in patients with spondyloarthropathy receiving anti-tumour necrosis factor \{alpha\} treatment. Ann Rheum Dis 2005;64:1137-40.

15. Stasko SA, Hardin BJ, Smith JD, Moylan JS, Reid MB. TNF signals via neuronal-type nitric oxide synthase and reactive oxygen species to depress specific force of skeletal muscle. J Appl Physiol (1985) 2013;114:1629-36.

16. Li YP, Lecker SH, Chen Y, Waddell ID, Goldberg AL, Reid MB. TNF-alpha increases ubiquitin-conjugating activity in skeletal muscle by up-regulating $\mathrm{UbcH} 2 /$ E220k. FASEB J 2003;17:1048-57. 